Volume I, No 1, Februari 2017

Hal 037-046

\title{
PENGELOLAAN KESELAMATAN KERJA NELAYAN DI PPI BATUKARAS KABUPATEN PANGANDARAN
}

\author{
Fishermen Safety Work Management in PPI Batukaras District Pangandaran \\ Oleh: \\ Ryan Suryadi Putra ${ }^{1}$, Fis Purwangka2*, Budhi Hascaryo Iskandar ${ }^{2}$ \\ ${ }^{1}$ Almuni Program Sarjana Departemen PSP FPIK IPB \\ ${ }^{2}$ Departemen PSP FPIK IPB \\ *Korespondensi: fis@psp-ipb.org
}

\begin{abstract}
ABSTRAK
Aktivitas nelayan di laut memiliki risiko yang tinggi karena kapal penangkap ikan beroperasi mulai dari perairan yang tenang hingga perairan dengan gelombang yang sangat besar. Masalah keselamatan kerja di laut dan keselamatan kapal untuk saat ini tidak hanya menjadi perhatian pemerintah Indonesia saja, namun telah menjadi perhatian dunia. Armada penangkapan ikan di pangkalan pendaratan ikan (PPI) Batukaras didominasi oleh armada penangkapan skala kecil. Data statistik Dinas Kelautan dan Perikanan Kabupaten Ciamis tahun 2011 menunjukkan bahwa jumlah armada tangkap yang ada di PPI Batukaras adalah sebanyak 281 unit dan semua armada berjenis motor tempel ukuran $<7$ Gross Tonnage (GT). Perhatian pemerintah daerah serta instansi yang bertanggung jawab terkait keselamatan kerja nelayan masih sangat minim. Tujuan dari penelitian ini untuk mengidentifikasi pengetahuan nelayan seputar keselamatan kerja, dan mengidentifikasi instansi pengelola keselamatan kerja nelayan. Seluruh data primer diperoleh dari kuesioner dan wawancara serta data sekunder berasal dari literatur. Hasil penelitian ini menunjukkan bahwa nelayan memiliki pengetahuan yang minim mengenai keselamatan kerja dan prosedur bekerja di kapal serta pengelolaan keselamatan kerja di PPI Batukaras tidak terlaksana dengan baik.
\end{abstract}

Kata kunci: keselamatan kerja, nelayan, PPI Batukaras

\begin{abstract}
Fisherman activities in the sea is high risk, especially fishing vessels operating from calm waters to waters with high waves. Safety issues and the safety of ships at sea for the moment not only concern Indonesian government it self, but has become the world's attention. Small scale fishing fleet dominated in PPI Batukaras, according to data from statistics of Department Marine and Fisheries District Ciamis in 2011 the number of fishing fleets in the PPI Batukaras is 281 units and all the manifold fleet size $<7$ GT outboard engine. Attention of local governments and related agencies responsible for safety of fishermen still less. The purpose of this study was to identify knowledge about fishing safety, and identify safety agencies from fishermen. The entire primary data obtained from questionnaires and interviews as well as secondary data derived from the literature. The results of this study indicate that the fishermen have minimal knowledge about safety and working procedures on board as well as the management of occupational safety in PPI Batukaras not performing well.
\end{abstract}

Keywords: fishermen, PPI Batukaras, safety work 


\section{PENDAHULUAN}

Kapal ikan, alat penangkap ikan, dan nelayan adalah tiga faktor yang mendukung keberhasilan dalam suatu operasi penangkapan ikan. Aktivitas nelayan di laut memiliki resiko yang tinggi karena kapal penangkap ikan beroperasi mulai dari perairan yang tenang hingga perairan dengan gelombang yang sangat besar. Faktor keselamatan kapal maupun nelayan merupakan hal yang perlu diperhatikan demi kesuksesan suatu operasi penangkapan ikan. Masalah keselamatan kerja di laut dan keselamatan kapal untuk saat ini tidak hanya menjadi perhatian pemerintah Indonesia saja, namun telah menjadi perhatian dunia.

Data yang diperoleh dari kesatuan patroli laut dan pantai (KPLP) dan komite nasional keselamatan transportasi (KNKT) menunjukkan bahwa kecelakaan kapal dari tahun 2003 - 2008 adalah sebesar 56\% untuk kapal tradisional, 17\% untuk kapal cargo, 8\% untuk ferry ro ro, 5\% untuk tanker, 3\% untuk kapal penumpang, 2\% untuk kapal ikan, 1\% untuk kapal container, dan 1\% untuk lain-lain (PT. Trans Asia Consultants 2009).

Kecelakaan yang terjadi diantaranya adalah kapal tenggelam, kapal kandas, kapal kebakaran, kapal tubrukan, dan kapal terbalik. Faktor yang menyebabkan terjadinya kecelakaan antara lain adalah faktor kesalahan manusia (human error), faktor alam, dan faktor teknis. Kecelakaan akibat faktor alam tidak dapat dihindari saat operasi penangkapan ikan, namun dengan meningkatkan kualitas sumber daya manusia dan faktor teknis diharapkan kecelakaan kapal dapat dihindari atau diminimalkan (PT. Trans Asia Consultants 2009).

Armada penangkapan di pangkalan pendaratan ikan (PPI) Batukaras didominasi oleh armada penangkapan skala kecil. Data statistik Dinas Kelautan dan Perikanan Kabupaten Ciamis tahun 2011 menunjukkan bahwa jumlah armada penangkapan yang ada di PPI Batukaras adalah sebanyak 281 unit dan semua armada berjenis motor tempel ukuran $<7$ gross tonnage (GT). Perhatian pemerintah daerah serta instansi yang bertanggung jawab terkait keselamatan kerja nelayan masih sangat minim. Oleh karena itu, penelitian mengenai pengelolaan keselamatan kerja nelayan sangat perlu dilakukan sebagai upaya meminimalisir tingkat kecelakaan nelayan di laut. Tujuan dari penelitian ini adalah untuk mengidentifikasi pengetahuan nelayan Batukaras seputar keselamatan kerja dan peran instansi pengelola keselamatan kerja nelayan di Batukaras.

\section{METODOLOGI}

\section{Metode Penelitian}

Penelitian ini dilaksanakan pada bulan Juli 2013 bertempat di Desa Batukaras, Kecamatan Cijulang, Kabupaten Pangandaran, Jawa Barat. Penelitian lapang ini dilakukan selama dua minggu, yakni pada pertengahan bulan Juli 2013 sampai dengan akhir bulan Juli 2013.

\section{Prosuder Pengambilan Data}

Data yang dikumpulkan ada dua jenis, yaitu data primer dan data sekunder. Data primer diperoleh dengan cara wawancara mendalam melalui kuesioner. Pengambilan data dilakukan dengan metode purposive sampling terhadap beberapa pihak yang berkepentingan dengan keselamatan kerja nelayan. Pihak-pihak tersebut yaitu syahbandar, kepala PPI, polisi air, kepala koperasi unit desa (KUD), serta beberapa tokoh kunci nelayan di PPI Batukaras. Data primer yang dikumpulkan antara lain pengetahuan nelayan mengenai keselamatan kerja, dan instansi yang berwenang dalam penanganan kecelakaan kerja di laut. Data sekunder diperoleh dengan cara penelusuran dokumen (peraturan) mengenai keselamatan kerja di laut pada instansi yang terkait dengan keselamatan kerja di laut.

\section{Prosedur Analisis Data}

Dalam penelitian ini setelah dilakukan pengumpulan data, maka data tersebut dianalisis untuk mendapatkan kesimpulan. Analisis data sebagai berikut :

1) Analisis deskriptif 
Metode analisis deskriptif yaitu usaha untuk mengumpulkan dan menyusun suatu data, kemudian dilakukan analisis terhadap data tersebut. Analisis deskriptif yakni data yang dikumpulkan berupa aspek kebijakan dan kelembagaan yang meliputi manfaat, implementasi dan kendala/kelemahan dari kebijakan yang ada. Analisis kelembagaan dilakukan dengan mengevaluasi keberadaan dan peran yang dilakukan oleh kelembagaan tersebut berkaitan dengan keselamatan kerja nelayan di laut.

\section{2) Content Analisys atau Analisis Isi}

Analisis yang digunakan dalam penelitian ini adalah analisis isi (Content Analisys). Di mana, data deskriptif sering hanya dianalisis menurut isinya, dan karena itu analisis semacam ini juga disebut analisis isi (Content Analisys) (Sumadi 1983). Dengan metode Content Analisys, dilakukan pengkajian secara mendalam mengenai isi atau materi yang terdapat pada dokumen (peraturan) mengenai keselamatan kerja di laut.

\section{HASIL DAN PEMBAHASAN}

\section{Perkembangan Armada Penangkapan Ikan}

Armada penangkapan ikan merupakan salah satu faktor yang mendukung keberhasilan dalam suatu operasi penangkapan. Armada penangkapan ikan yang digunakan berupa kapal perikanan, yang didefinisikan sebagai kapal, perahu, atau alat apung lainnya yang dipergunakan untuk melakukan penangkapan ikan, mendukung operasi penangkapan ikan, pembudidayaan ikan, pengangkutan ikan, pengolahan ikan, pelatihan perikanan, dan penelitian/eksplorasi perikanan (Undang-Undang RI No.31 Tahun 2004).

Selama periode 2005-2011 jumlah armada penangkapan ikan di PPI Batukaras mengalami fluktuasi pada jenis motor tempel dan perahu tanpa motor. Faktor yang mempengaruhinya adalah teknologi dan jumlah nelayan. Kapal motor yang memiliki ukuran 5-10 gross tonnage (GT) tidak mengalami perubahan, karena selama periode tersebut tidak ada nelayan yang mengoperasikan kapal motor, disebabkan nelayan setempat tidak memiliki modal yang cukup dalam pengoperasiannya. Pada Tabel 1 dapat dilihat jumlah serta jenis armada penangkapan ikan di Kecamatan Cijulang periode 2005-2011.

\section{Pengetahuan Nelayan Seputar Keselamatan Kerja}

Nelayan di pangkalan pendaratan ikan (PPI) Batukaras merupakan nelayan tradisional yang dominan menggunakan alat tangkap gillnet. Nelayan kurang memahami mengenai keselamatan kerja di laut dan prosedur yang ada serta hanya mengandalkan pengetahuan yang minim mengenai keselamatan. Nelayan pada biasanya hanya melihat tanda-tanda dari alam sebelum melaut dan tanpa membawa

Tabel 1 Data perkembangan armada penangkapan ikan kecamatan cijulang tahun 2005-2011

\begin{tabular}{llccccccc}
\hline \multirow{2}{*}{ NO } & $\begin{array}{l}\text { JENIS ARMADA } \\
\text { TANGKAP } \\
\text { (UNIT) }\end{array}$ & \multicolumn{6}{c}{ Kecamatan Cijulang } \\
\cline { 2 - 8 } & 2005 & 2006 & 2007 & 2008 & 2009 & 2010 & 2011 \\
\hline 1 & $\begin{array}{l}\text { Kapal Motor (KM) } \\
>5-10 \text { GT }\end{array}$ & 0 & 0 & 0 & 0 & 0 & 0 & 0 \\
2 & $\begin{array}{l}\text { Motor Tempel } \\
\text { (MT) }\end{array}$ & 225 & 148 & 320 & 281 & 281 & 281 & 281 \\
3 & $\begin{array}{l}\text { Perahu Tanpa } \\
\text { Motor (PTM) }\end{array}$ & 30 & 30 & 30 & 0 & 0 & 0 & 0 \\
\hline JUMLAH & 255 & 178 & 350 & 281 & 281 & 281 & 281
\end{tabular}

Sumber: Dinas Kelautan dan Perikanan Kab. Ciamis (2005-2011) 
peralatan keselamatan yang seharusnya dibawa.

Alat komunikasi yang digunakan berupa telepon genggam karena jarak melaut yang relatif dekat, maksimal 5 mil laut dan sinyal telepon genggam masih menjangkau daerah penangkapan ikan tersebut. Kecelakaan yang pernah terjadi di lapangan didominasi oleh kapal tenggelam, terbalik, hanyut, serta kecelakaan kerja. Kejadian kebakaran dan tubrukan sangat jarang terjadi. Kecelakaan kerja yang biasa terjadi adalah nelayan terbelit oleh jaring sehingga tangan terluka terkena mata pancing, hal tersebut dikarenakan kurang hati-hatinya korban ketika melakukan operasi penangkapan ikan. Penanganannya dilakukan dengan pertolongan pertama pada kecelakaan namun tidak diobati dengan alat P3K hanya dibersihkan dengan air dan luka dibalut dengan kain seadanya. Menurut penuturan nelayan, apabila terjadi kecelakaan yang menyebabkan perahu terbalik atau tenggelam, nelayan hanya mengandalkan jerigan sebagai pelampung atau menggunakan katir yang seyogyanya digunakan sebagai alat penyeimbang perahu.
Kartu anggota Himpunan Nelayan Seluruh Indonesia (HNSI) merupakan sebuah jaminan yang pasti bagi para nelayan apabila terjadi kecelakaan perahu yang mereka tumpangi hanyut. Nelayan di PPI Batukaras dominan menggunakan kapal kecil dengan ukuran <7 GT. Jumlah awak kapal pada kapal tersebut 2 orang, dengan pembagian kerja di kapal sebagai tekong dan ABK. Pembagian kerja pada perikanan skala kecil ini tidak terlalu terlihat karena keduanya memiliki tugas yang sama di kapal dalam operasi penangkapan ikan, namun untuk tekong, tanggung jawab yang dibebankan adalah navigasi serta mesin kapal, namun ketika dilakukan operasi penangkapan ikan, tekong dan ABK bekerja sama. Terkadang tekong dan ABK hanyalah panggilan sebagai pembeda antara pemilik kapal dan anak buahnya.

Dalam menciptakan keselamatan kerja tentunya harus didukung oleh keterampilan dan pengetahuan yang wajib dimiliki orangorang yang terkait di dalamnya. Pada Gambar 1 disampaikan hasil kuesioner terhadap nelayan PPI Batukaras mengenai pengetahuan tentang keselamatan kerja, pengetahuan mengenai aturan keselamatan kerja, pengetahuan akan pentingnya prosedur kerja
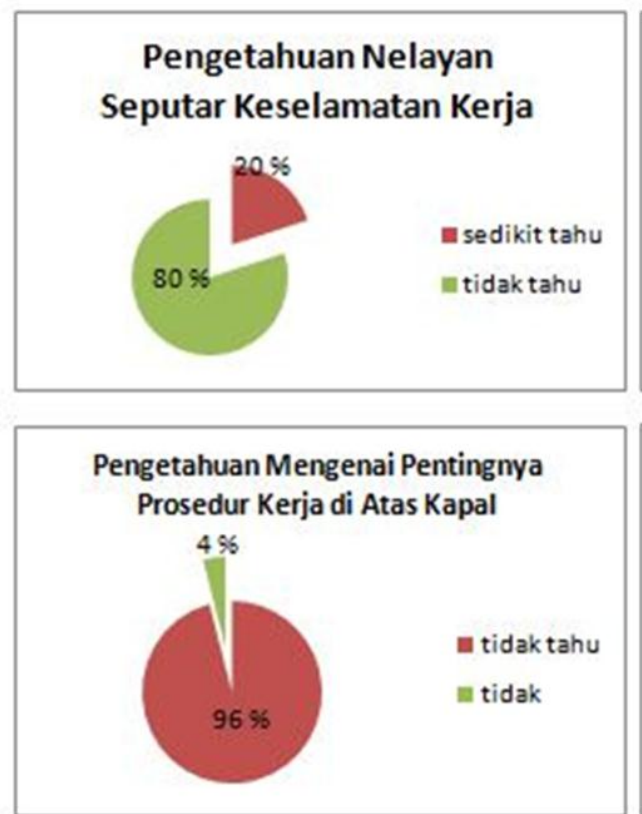

Sumber: Hasil Wawancara Nelayan (diolah)

Gambar 1 Hasil wawancara nelayan terkait pengetahuan dan kesadaran terkait keselamatan kerja
Pengetahuan Nelayan Mengenai Aturan Terkait Keselamatan Kerja

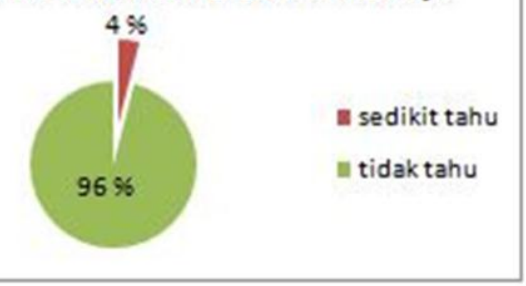

\section{Kesadaran Nelayan Akan Keselamatan Kerja}

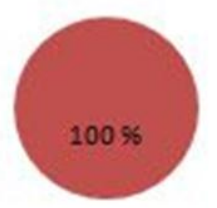

aya 
di atas kapal, dan kesadaran nelayan akan keselamatan kerja.

Dari Gambar 1 terlihat bahwa nelayan yang memiliki pengetahuan mengenai keselamatan kerja sangat minim, 20\% nelayan sedikit mengetahui tentang keselamatan kerja dan $80 \%$ tidak mengetahui mengenai keselamatan kerja. Aturan terkait keselamatan kerja yang diketahui nelayan sangat minim, 96\% diantaranya tidak mengetahui bahwa ada aturan mengenai keselamatan kerja. Nelayan hanya mengetahui keselamatan kerja tergantung pribadi masing-masing orang yang menjalaninya saja, apabila cuaca baik maka nelayan akan melaut namun apabila cuaca buruk nelayan tidak akan melaut. 4\% dari nelayan sedikit mengetahui aturan seputar keselamatan kerja. Nelayan hanya sebatas mengetahui adanya aturan namun tidak dapat menyebutkan aturan yang berlaku.

Pengaplikasian secara tidak sengaja oleh nelayan adalah dengan menggunakan jerigen atau katir yang digunakan sebagai pelampung apabila terjadi kecelakaan kapal yang membuat kapal tenggelam. Kesadaran nelayan akan keselamatan kerja seharusnya didukung oleh kompetensi yang memadai. Menurut IMO (2007), Nakhoda kapal kecil harus memiliki kompetensi kerja yang memadai dalam mengoperasikan kapal secara aman dan selamat, mengelola kapal dengan baik secara terus menerus, meliputi:
2. Menangani keadaan darurat dan menggunakan radio komunikasi untuk meminta pertolongan;

3. Pertolongan Pertama pada Kecelakaan (P3K);

4. Mengolah gerak kapal di laut, di pelabuhan dan selama operasi penangkapan;

5. Navigasi;

6. Kondisi cuaca dan ramalan cuaca;

7. Stabilitas kapal;

8. Penggunaan sistem signal;

9. Pencegahan kecelakaan;

10. Peraturan Pencegahan Tubrukan di Laut;

11. Memahami dan meminimalkan risiko operasi penangkapan ikan.

Fakta yang ada di lapangan, human error dapat menjadi pemicu terjadinya kecelakaan kerja. Kompetensi nelayan yang ditemukan di lapangan sangat minim, bertolak belakang dengan standar kompetensi yang direkomendasikan oleh IMO dalam mengoperasikan kapal secara aman dan selamat. Hanya kompetensi dalam perawatan mesin dan kondisi cuaca dan ramalan cuaca yang rata-rata dimiliki oleh nelayan di PPI Batukaras. Hal tersebut cukup membuktikan bahwa kesadaran akan keselamatan kerja tinggi namun pengetahuan dan kompetensi yang dimiliki minim.

1. Pengoperasian dan perawatan mesin;

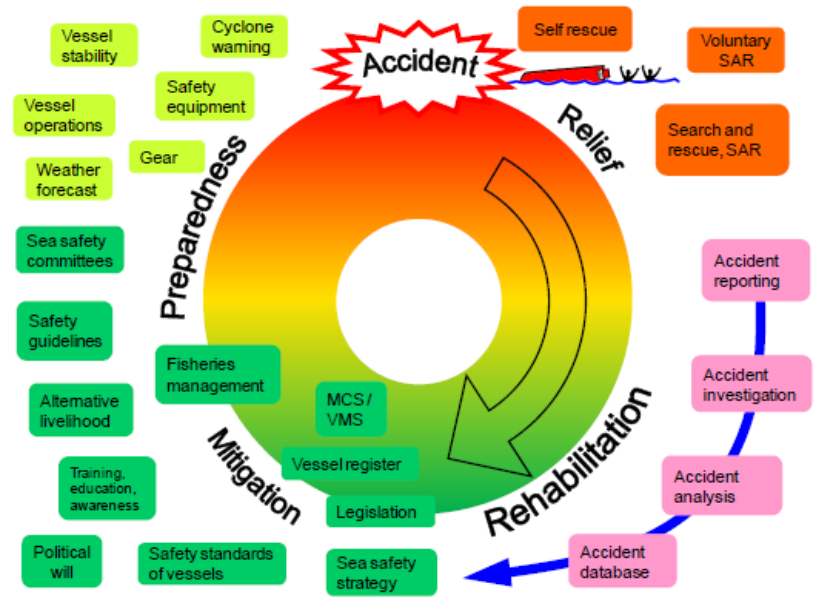

Sumber: Danielsson (2010)

Gambar 2 Siklus manajemen keamanan laut (Danielsson 2010) 


\section{Instansi Pengelola Keselamatan Kerja Nelayan}

Menurut Danielsson (2010) diperlukan pengelolaan yang berkelanjutan terhadap peningkatan keamanan bagi nelayan. Pengelolaan tersebut dapat diilustrasikan dalam siklus manajemen keselamatan laut yang tertera pada gambar 2. Siklus ini bertujuan untuk memberikan informasi sistem pelaporan kecelakaan di laut untuk dimasukan ke dalam sistem manajemen keselamatan dalam rangka meningkatkan keamanan bagi nelayan. Hal ini juga mencerminkan pentingnya pendekatan holistik yang melibatkan semua pengambil kebijakan. Keamanan pada siklus manajemen laut ditandai dengan perbaikan sistem yang berkelanjutan untuk keselamatan nelayan.

Hasil identifikasi peran pengelolaan keselamatan kerja nelayan didapatkan dari analisis kebijakan kelembagaan yang meliputi manfaat, implementasi, dan kendala/ kelemahan dari kebijakan yang ada. Analisis kelembagaan dilakukan dengan mengevaluasi keberadaan dan peran yang dilakukan oleh kelembagaan tersebut berkaitan dengan keselamatan kerja nelayan di laut.

Gambar 3 menjelaskan mengenai siklus manajemen keamanan laut di PPI Batukaras. Terdapat empat kategori dalam siklus ini, yakni mitigasi dan persiapan yang termasuk dalam langkah proaktif serta bantuan dan rehabilitasi yang termasuk dalam langkah reaktif. Bila dibandingkan antara kondisi yang terjadi di lapangan dengan literatur, kategori yang terlaksana di lapangan adalah kategori persiapan dan bantuan namun pada kategori persiapan tidak semua aspek terlaksana.

Persiapan merupakan kategori pertama yang terlaksana. Pada kategori ini aspek yang terlaksana adalah alat tangkap, stabilitas kapal, dan pengoperasian kapal. Ketiga aspek yang terlaksana merupakan kegiatan yang sudah biasa nelayan lakukan sebelum melakukan operasi penangkapan ikan. Alat tangkap dipersiapkan agar aktivitas penangkapan dapat dilakukan dengan baik, kerusakan yang terdapat pada alat tangkap selalu diperbaiki agar mendapatkan hasil tangkapan yang optimal. Dalam hal pengoperasian kapal selalu dilakukan persiapan dengan cara memeriksa mesin tempel yang akan digunakan serta membawa cadangan bahan bakar. Selanjutnya pada aspek stabilitas kapal dipersiapkan dengan memasang alat penyeimbang tambahan pada kapal yang disebut dengan katir.

Bantuan merupakan kategori kedua yang terlaksana. Penyelamatan diri dilakukan ketika terjadi kecelakaan, dilakukan oleh korban dengan mempertahankan diri agar tidak tenggelam menggunakan jerigen atau katir sebagai pelampung. Aspek selanjutnya yang terlaksana adalah pencarian dan penyelamatan sukarela yang dilakukan oleh rekan sesama nelayan namun ketika aspek tersebut tidak berhasil menyelamatkan korban maka tim SAR melaksanakan tugasnya untuk mencari dan menyelamatkan korban kecelakaan.

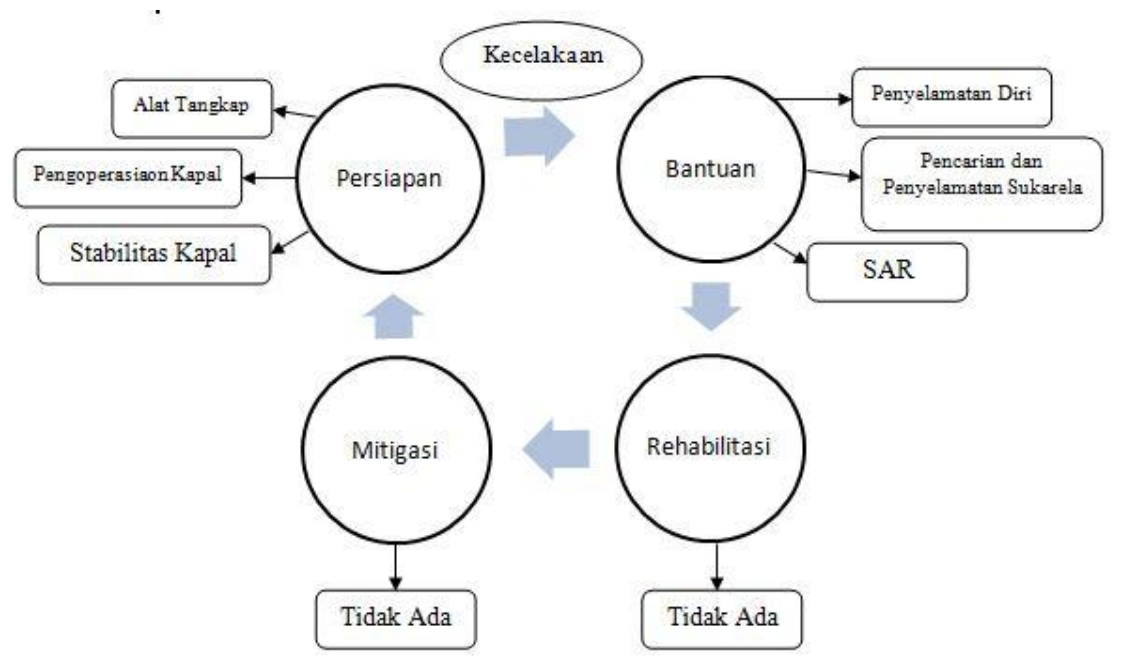

Gambar 3 Siklus manajemen keamanan laut PPI Batukaras 


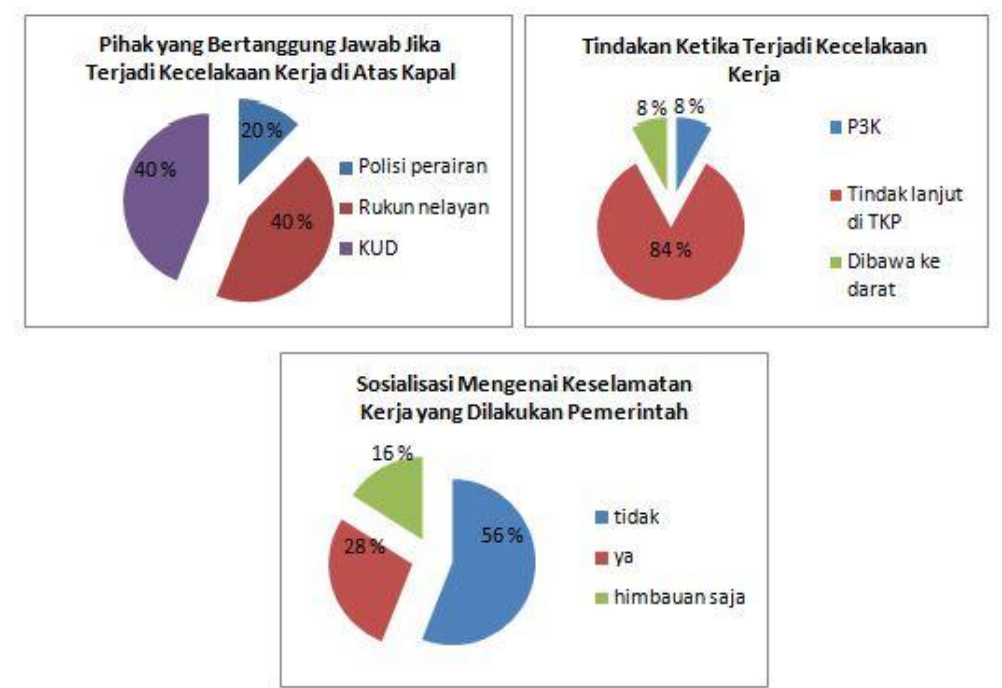

Sumber: Wawancara Nelayan PPI Batukaras (diolah)

Gambar 4 Peran instansi pemerintahan \& organisasi nelayan serta penanganan ketika terjadi kecelakaan kerja

Pada Gambar 4 digambarkan mengenai pihak yang bertanggung jawab apabila terjadi kecelakaan di kapal, penanganan yang dilakukan, serta peran pemerintah dalam sosialisasi mengenai keselamatan kerja.

Koordinasi yang terlihat di PPI Batukaras adalah koordinasi antara KUD, rukun nelayan, dan polisi perairan. Tidak terlihat instansi lain yang seharusnya terlibat dalam kesehatan dan keselamatan kerja nelayan. Hal tersebut bertolak belakang dengan pasal 31 ayat 4 yang tertuang dalam Peraturan Menteri Kelautan Dan Perikanan Republik Indonesia Nomor Per.08/Men/2012 tentang Kepelabuhanan Perikanan, yakni instansi/unit kerja terkait di pelabuhan perikanan sebagaimana dimaksud pada ayat (3) terdiri dari:

1. Pemerintah daerah provinsi dan kabupaten/kota;

2. TNI/POLRI;
3. Imigrasi;

4. Bea dan Cukai;

5. Kesehatan Pelabuhan;

6. Perhubungan Laut;

7. Pengawasan dan pengendalian sumber daya kelautan dan perikanan;

8. Pengolahan dan pemasaran hasil perikanan;

9. Penelitian dan pengembangan kelautan dan perikanan;

10. Pengembangan sumber daya manusia kelautan dan perikanan;

11. Karantina ikan;

12. BUMN dan/atau BUMD; dan/atau

13. Instansi terkait lainnya.

Kecelakaan kapal berupa kapal terbalik, hanyut, dan tenggelam merupakan kecelakaan fatal yang sering terjadi di lapangan. Penanganan yang dilakukan untuk ketiga kecelakaan tersebut adalah dengan menindaklanjuti di lapangan, yaitu apabila ada nelayan lain yang posisinya dekat dengan tempat kejadian perkara (TKP) maka nelayan tersebut

Tabel 2 Peraturan nasional yang berhubungan dengan keselamatan kerja nelayan

\begin{tabular}{llc}
\hline No & Peraturan & Latar Belakang \\
\hline 1 & Undang-Undang Republik Indonesia Nomor 17 & UU ini mengatur tentang pelayaran \\
& Tahun 2008 & \\
2 & $\begin{array}{l}\text { Peraturan Menteri Kelautan Dan Perikanan } \\
\text { Republik Indonesia Nomor Per.08/Men/2012 }\end{array}$ & Tentang Kepelabuhanan Perikanan \\
\hline
\end{tabular}

Sumber : Purwangka (2013), diolah 
menolong korban, namun jika tidak ada nelayan lain di sekitar TKP akan dilakukan pencarian oleh tim SAR yang merupakan anggota rukun nelayan yang dibentuk oleh KUD setempat serta bantuan dari polisi perairan apabila dibutuhkan. Faktor yang mempengaruhi kecelakaan fatal tersebut merupakan faktor cuaca. Nelayan hanya mengandalkan prediksi cuaca secara tradisional dengan cara melihat tanda-tanda alam dengan melihat langit.

Peran syahbandar sebagai lembaga yang memiliki tugas dalam mengatur kedatangan dan keberangkatan nelayan belum terlihat padahal menurut Peraturan Menteri Kelautan dan Perikanan Republik Indonesia Nomor Per.08/Men/2012 tentang Kepelabuhanan Perikanan pasal 30 ayat 1 point (a) dijelaskan bahwa syahbandar di pelabuhan perikanan mempunyai tugas dan wewenang mengatur kedatangan dan keberangkatan kapal perikanan.

Upaya dalam pencarian korban ketika terjadi kecelakaan kapal dilakukan, tidak terlihat partisipasi syahbandar. Implementasi dari Peraturan Menteri Kelautan dan Perikanan Republik Indonesia Nomor Per.08 /Men/2012 tentang Kepelabuhanan Perikanan pasal 30 ayat 1 point (k) yang menyebutkan bahwa syahbandar di pelabuhan perikanan mempunyai tugas dan wewenang untuk melaksanakan bantuan pencarian dan keselamatan tidak terlihat justru yang terjadi di lapangan pihak yang terlibat adalah KUD, dan rukun nelayan. Polisi perairan datang ke lokasi apabila ada laporan dari nelayan. Melihat kondisi tersebut sebaiknya wewenang tersebut diserahkan kepada KUD atau organisasi rukun nelayan setempat mengingat penuturan dari kepala Syahbandar Pangandaran yang menjelaskan bahwa untuk kapal $<7 \quad$ GT wewenangnya telah diserahkan pada unit pelaksana teknis daerah namun pengelolaannya masih belum optimal.

Kebijakan-kebijakan yang ada mengenai pelayaran dan keselamatan belum menyentuh sektor perikanan skala kecil. Belum adanya regulasi yang mengatur keselamatan kapal yang berukuran <7 GT menyebabkan im- plementasi dari kebijakan yang ada sulit dilaksanakan.

Tabel 3 menunjukkan bahwa regulasi nasional keselamatan kerja nelayan belum sepenuhnya menyentuh sektor perikanan skala kecil. Beberapa catatan dari isi naskah pada Tabel 3 menjelaskan bahwa regulasi berlaku umum namun fakta di lapangan tidak terlihat implementasi yang dilakukan dan keadaan bertolak belakang dengan regulasi yang ada. Tumpang tindih aturan dan kebijakan yang terjadi disebabkan kurangnya koordinasi dan komunikasi antar instansi yang berwenang sehingga implementasi tidak efektif.

Terjadi tumpang tindih aturan dan kepentingan fungsi syahbandar dan direktorat kepolisian perairan (Ditpolair) dalam pemberian bantuan pencarian dan keselamatan (SAR) di laut/perairan. Peraturan Menteri Kelautan Dan Perikanan Republik Indonesia Nomor Per.08/Men/2012 tentang Kepelabuhanan Perikanan pasal 30 ayat 1 point (k) yang menyebutkan bahwa syahbandar di pelabuhan perikanan mempunyai tugas dan wewenang untuk melaksanakan bantuan pencarian dan keselamatan, dan Peraturan Kapolri Nomor 22 Tahun 2010 tentang Susunan Organisasi dan Tata Kerja Pada Tingkat Kepolisian Daerah pasal 202 ayat 3 point (c) menyatakan hal yang serupa yaitu Ditpolair menyelenggarakan fungsi pemberian bantuan SAR di laut/perairan. Jika kedua instansi berkoordinasi dengan baik, fungsi dan wewenang yang dimiliki oleh kedua instansi dapat dilaksanakan sebagaimana mestinya. Dampak wewenang pencarian dan keselamatan (SAR) yang tidak terlaksana diminimalisir dengan adanya tim SAR sukarela dari KUD. Tim SAR tersebut menjadi bantuan yang sangat berpengaruh dalam usaha menyelamatkan nelayan dalam kondisi yang berbahaya. 
Tabel 3 Regulasi nasional keselamatan kerja nelayan

\begin{tabular}{|c|c|c|}
\hline No & Isi naskah & Catatan \\
\hline 1 & Keselamatan kapal perikanan & Tidak termasuk kapal $<12 \mathrm{~m}$ \\
\hline 2 & Panduan prosedur keselamatan kapal & Tidak termasuk kapal $<12 \mathrm{~m}$ \\
\hline 3 & $\begin{array}{l}\text { Persyaratan desain, konstruksi dan } \\
\text { peralatannya (distressed signal, alat } \\
\text { komunikasi) }\end{array}$ & $\begin{array}{l}\text { Tidak termasuk kapal }<12 \mathrm{~m} \text {, berlaku } \\
\text { Umum, terjadi tumpang tindih aturan }\end{array}$ \\
\hline 4 & Panduan desain, konstruksi dan peralatannya & Tidak termasuk kapal < $12 \mathrm{~m}$ \\
\hline 5 & $\begin{array}{l}\text { Keselamatan saat berlayar (mengemudi, } \\
\text { lampu navigasi, dan alat lainnya) }\end{array}$ & Berlaku umum \\
\hline 6 & SAR untuk pelayaran dan kecelakaan & $\begin{array}{l}\text { Berlaku umum, tumpang tindih } \\
\text { kepentingan }\end{array}$ \\
\hline 7 & Keselamatan kerja nelayan & Tidak termasuk kapal $<12 \mathrm{~m}$ \\
\hline 8 & Standar kesehatan nelayan & Berlaku umum \\
\hline 9 & Persyaratan keterampilan dan tugas nelayan & $\begin{array}{l}\text { Tidak ada penerapan dan pengawasan } \\
\text { pada kapal berukuran kecil }\end{array}$ \\
\hline 10 & Pedoman pelatihan nelayan & Berlaku umum \\
\hline 11 & Pelatihan kejuruan nelayan & $\begin{array}{l}\text { Berlaku umum, tidak termasuk kapal } \\
\text { berukuran }<12 \mathrm{~m}\end{array}$ \\
\hline 12 & $\begin{array}{l}\text { Tanggung jawab pemerintah terhadap } \\
\text { keselamatan dan kesehatan nelayan }\end{array}$ & Berlaku umum \\
\hline 13 & Pendataan & $\begin{array}{l}\text { Berlaku umum, tumpang tindih } \\
\text { kepentingan, tidak valid, minim }\end{array}$ \\
\hline 14 & Pengelolaan (organisasi dan fungsi) & $\begin{array}{l}\text { Berlaku umum, tumpang tindih } \\
\text { kepentingan }\end{array}$ \\
\hline 15 & $\begin{array}{l}\text { Penindakan pelanggaran pada keselamatan } \\
\text { kerja nelayan }\end{array}$ & $\begin{array}{l}\text { Berlaku umum, keterbatasan alat dan } \\
\text { personil }\end{array}$ \\
\hline
\end{tabular}

Sumber : Purwangka (2013), diolah

\section{KESIMPULAN}

Pengetahuan nelayan di PPI Batukaras seputar keselamatan kerja sangat minim, nelayan tidak mengetahui adanya peraturan mengenai keselamatan kerja serta tidak mengetahui prosedur bekerja di atas kapal namun kesadaran akan keselamatan kerja sangat tinggi. Selain itu, Pengelolaan keselamatan kerja di PPI Batukaras belum terlaksana dengan baik, kebijakan tidak diimplementasikan oleh instansi yang berwenang. Pelaksanaan pengelolaan keselamatan kerja sifatnya insidental dilakukan oleh pihak KUD dan rukun nelayan.

\section{DAFTAR PUSTAKA}

[BAKORKAMLA] Badan Koordinasi Keamanan Laut. 2009. Pedoman Khusus Keselamatan dan Keamanan Pelayaran. Jakarta (ID): BAKORKAMLA.

Danielsson. 2010. Safety At Sea For Small-Scale Fisheries In Developing Countries. Rome (IT): Food And Agriculture Organization (FAO). 
[Depnakertrans] Departemen Tenaga Kerja dan Transmigrasi. 1996. Peraturan Menteri Tenaga Kerja nomor : Per. 05/Men/1996 tentang Sistem Manajemen Keselamatan dan Kesehatan Kerja. Jakarta (ID): Depnakertrans.

[DKP Kabupaten Ciamis] Dinas Kelautan dan Perikanan Kabupaten Ciamis. 2011. Laporan Statistik Perikanan Tangkap dan Budidaya Kabupaten Ciamis. Ciamis (ID): DKP Kabupaten Ciamis.

[IMO] International Maritime Organization. 1960. International Convention for the Safety of Life at Sea. London (EN): International Maritime Organization (IMO).

[IMO] International Maritime Organization. 2007. Any Other Business. Outcome of SLF 50. STW 39/11/1. Sub Committee on Standard of Training and Watchkeeping. 39 th Session. London (EN): International Maritime Organization (IMO).

[KKP] Kementerian Kelautan dan Perikanan. 2012. Peraturan Menteri Kelautan dan Perikanan Nomor Per.08/Men/2012 tentang Kepelabuhanan Perikanan. Jakarta (ID): KKP.

[POLRI] Kepolisian Republik Indonesia. 2010. Peraturan Kepala Kepolisian Republik Indonesia Nomor 22 Tahun 2010 tentang Susunan Organisasi dan Tata Kerja Pada Tingkat Kepolisian Daerah. Jakarta (ID): POLRI.

Pemerintah Republik Indonesia. 2004. Undang-Undang Republik Indonesia Nomor 31 Tahun 2004 Tentang Perikanan. Jakarta (ID): Sekretariat Negara.

Pemerintah Republik Indonesia. 2008. Undang-Undang Republik Indonesia Nomor 17 Tahun 2008 Tentang Pelayaran. Jakarta (ID): Sekretariat Negara.

PT. Trans Asia Consultans. 2009. Kajian Analisis Trend Kecelakaan Transportasi Laut Tahun 2003 2008. Jakarta (ID).

Purwangka F. 2013. Keselamatan kerja nelayan pada operasi penangkapan ikan menggunakan payang di Palabuhanratu, Jawa Barat [disertasi]. Bogor (ID): Institut Pertanian Bogor.

Sumadi Suryabrata. 1983. Metodologi Penelitian. Jakarta (ID): CV. Rajawali. 